\title{
Numerical Analysis of a Linear-Implicit Average Scheme for Generalized Benjamin-Bona-Mahony-Burgers Equation
}

\author{
Hai-tao Che, ${ }^{1,2}$ Xin-tian Pan, ${ }^{2}$ Lu-ming Zhang, ${ }^{3}$ and Yi-ju Wang ${ }^{1}$ \\ ${ }^{1}$ School of Management Science, Qufu Normal University, Rizhao 276800, China \\ ${ }^{2}$ School of Mathematics and Information Science, Weifang University, Weifang 261061, China \\ ${ }^{3}$ Department of Mathematics, Nanjing University of Aeronautics and Astronautics, \\ Nanjing 210016, China \\ Correspondence should be addressed to Hai-tao Che, haitaoche@163.com
}

Received 14 October 2011; Accepted 21 December 2011

Academic Editor: Yuantong Gu

Copyright (C) 2012 Hai-tao Che et al. This is an open access article distributed under the Creative Commons Attribution License, which permits unrestricted use, distribution, and reproduction in any medium, provided the original work is properly cited.

\begin{abstract}
A linear-implicit finite difference scheme is given for the initial-boundary problem of GBBMBurgers equation, which is convergent and unconditionally stable. The unique solvability of numerical solutions is shown. A priori estimate and second-order convergence of the finite difference approximate solution are discussed using energy method. Numerical results demonstrate that the scheme is efficient and accurate.
\end{abstract}

\section{Introduction}

The generalized Benjamin-Bona-Mahony-Burgers (GBBM-Burgers) equation is in the form [1]

$$
u_{t}-u_{x x t}-\alpha u_{x x}+\beta u_{x}+u^{p} u_{x}=0
$$

where $\alpha>0, \beta$ are constants, $p \geq 1$ is an integer, and $u(x, t)$ represents the velocity of fluid in the horizontal direction $x$. When $p=1,(1.1)$ is called as the Benjamin-Bona-Mahony-Burgers (BBM-Burgers) equation. In the special case, when $\alpha=0,(1.1)$ is described as the generalized Benjamin-Bona-Mahony equation

$$
u_{t}-u_{x x t}+u_{x}+u^{p} u_{x}=0
$$


The Equation (1.2) which is usually called as the generalized regularized long-wave equation proposed by Peregrine [2] and Benjamin et al. [3], so-called generalized Benjamin-BonaMahony equation, has been studied by many authors [4-7]. This equation features a balance between the nonlinear dispersive effect but takes no account of dissipation.

In recent years, a vast amount of work and computation has been devoted to the initial value problem for the GBBM-Burgers equation. In [1], Al-Khaled et al. studied the GBBMBurgers by Decomposition method. In [8], Hayashi et al. investigated large time asymptotics of solutions to the BBM-Burgers equation. In [9], Jiang and $\mathrm{Xu}$ investigated the asymptotic behavior of solutions of the initial-boundary value problem for the GBBM-Burgers equations. In [10], Yin et al. studied the large time behavior of traveling wave solutions to the Cauchy problem of the GBBM-Burgers equations. In [11], Mei studied the large time behavior of global solutions to the Cauchy problem of GBBM-Burgers equations. In [12], Kondo and Webler studied the global existence of solutions for multidimensional GBBM-Burgers equations. Kinami et al. discussed the Cauchy problem of the GBBM-Burgers equations by Fourier transform method and energy method [13]. However, there are few studies on finite difference approximations for (1.1) which we consider in this paper.

In a recent work [14], we have made some preliminary computation by proposing a linearized difference scheme for GRLW equation which is unconditionally stable and reduces the computational work, and the numerical results are encouraging. In this paper, we continue our work and propose a linear-implicit difference scheme for generalized BBMBurgers equation which is unconditionally stable and second-order convergent.

In this paper, we consider the following initial-boundary value problem of the GBBMBurgers equation

$$
\begin{gathered}
u_{t}-u_{x x t}-\alpha u_{x x}+\beta u_{x}+u^{p} u_{x}=0, \quad x \in\left[x_{L}, x_{R}\right], t \in[0, T], \\
u(x, 0)=u_{0}(x), \quad x \in\left[x_{L}, x_{R}\right], \\
u\left(x_{L}, t\right)=u\left(x_{R}, t\right)=0, \quad t \in[0, T] .
\end{gathered}
$$

An outline of the paper is as follows. In Section 2, we describe a linear-implicit finite difference scheme for the GBBM-Burgers equation and prove the error estimates of 2 order. In Section 3, we show that the scheme is uniquely solvable. In Section 4, convergence and stability of the scheme are proved. In Section 5, numerical results are provided to test the theoretical results.

\section{Finite Difference Scheme and Estimate for the Difference Solution}

As usual, the following notations will be used:

$$
x_{j}=x_{L}+j h, \quad t_{n}=n \tau, \quad 0 \leq j \leq J, 0 \leq n \leq N=\left[\frac{T}{\tau}\right],
$$

where $h=\left(x_{R}-x_{L}\right) / J$ and $\tau$ are the uniform spatial and temporal step sizes, respectively,

$$
\left(u_{j}^{n}\right)_{x}=\frac{u_{j+1}^{n}-u_{j}^{n}}{h}, \quad\left(u_{j}^{n}\right)_{\bar{x}}=\frac{u_{j}^{n}-u_{j-1}^{n}}{h},
$$


Journal of Applied Mathematics

$$
\begin{gathered}
\left(u_{j}^{n}\right)_{\widehat{x}}=\frac{u_{j+1}^{n}-u_{j-1}^{n}}{2 h}, \quad\left(u_{j}^{n}\right)_{\widehat{t}}=\frac{u_{j}^{n+1}-u_{j}^{n-1}}{2 \tau}, \\
\bar{u}_{j}^{n}=\frac{u_{j}^{n+1}+u_{j}^{n-1}}{2}, \quad\left(u^{n}, v^{n}\right)=h \sum_{j} u_{j}^{n} v_{j}^{n}, \\
\left\|u^{n}\right\|^{2}=\left(u^{n}, u^{n}\right), \quad\left\|u^{n}\right\|_{\infty}=\sup _{j}\left|u_{j}^{n}\right| .
\end{gathered}
$$

Let $u_{j}^{n}$ denote the approximation of $u\left(x_{j}, t_{n}\right), Z_{h}^{0}=\left\{u=\left(u_{j}\right) \mid u_{0}=u_{J}=0,1 \leq j \leq J\right\}$. In this paper, we will denote $C$ as a generic constant independent of step sizes $h$ and $\tau$.

We propose a three-level linear-implicit difference scheme for the solution of the problem (1.3)

$$
\begin{gathered}
\left(u_{j}^{n}\right)_{\hat{t}}-\left(u_{j}^{n}\right)_{x \bar{x} \hat{t}}-\alpha\left(\bar{u}_{j}^{n}\right)_{x \bar{x}}+\beta\left(u_{j}^{n}\right)_{\hat{x}}+\frac{1}{p+2}\left[\left(u_{j}^{n}\right)^{p}\left(\bar{u}_{j}^{n}\right)_{\hat{x}}+\left(\left(u_{j}^{n}\right)^{p} \bar{u}_{j}^{n}\right)_{\hat{x}}\right]=0, \\
1 \leq j \leq J-1,1 \leq n \leq N-1, \\
u_{j}^{0}=u_{0}\left(x_{j}\right), \quad 1 \leq j \leq J-1, \\
u_{j}^{1}-\left(u_{j}^{1}\right)_{x \bar{x}}=u_{0}\left(x_{j}\right)+\frac{d^{2} u_{0}}{d x^{2}}\left(x_{j}\right)-\tau\left[\beta \frac{d u_{0}}{d x}\left(x_{j}\right)-\alpha \frac{d^{2} u_{0}}{d x^{2}}\left(x_{j}\right)+u_{0}^{p}\left(x_{j}\right) \frac{d u_{0}}{d x}\left(x_{j}\right)\right], \\
u_{0}^{n}=u_{J}^{n}=0, \quad 1 \leq n \leq N-1 .
\end{gathered}
$$

For convenience, the last term of (2.3) is defined by

$$
\psi\left(u^{n}, \bar{u}^{n}\right)=\frac{1}{p+2}\left[\left(u_{j}^{n}\right)^{p}\left(\bar{u}_{j}^{n}\right)_{\widehat{x}}+\left(\left(u_{j}^{n}\right)^{p} \bar{u}_{j}^{n}\right)_{\widehat{x}}\right]
$$

Lemma 2.1 (see [15]). For any two mesh functions $u, v \in Z_{h^{\prime}}^{0}$ one has

$$
\left(u_{x}, v\right)=-\left(u, v_{\bar{x}}\right), \quad\left((u)_{x \bar{x}}, v\right)=-\left(u_{x}, v_{x}\right), \quad\left((u)_{x \bar{x}}, u\right)=-\left(u_{x}, u_{x}\right)=-\left\|u_{x}\right\|^{2} .
$$

Lemma 2.2. For any mesh function $u \in Z_{h^{\prime}}^{0}$ one has

$$
\left(\psi\left(u^{n}, \bar{u}^{n}\right), \bar{u}^{n}\right)=0 .
$$


Proof. For $u^{n} \in Z_{h^{\prime}}^{0}$ one has

$$
\begin{aligned}
\left(\psi\left(u^{n}, \bar{u}^{n}\right), \bar{u}^{n}\right)= & \frac{1}{8(p+2)} \sum_{j}\left[\left(u_{j}^{n}\right)^{p}\left(u_{j+1}^{n+1}-u_{j-1}^{n+1}+u_{j+1}^{n-1}-u_{j-1}^{n-1}\right)\right. \\
& \left.\quad+\left(u_{j+1}^{n}\right)^{p}\left(u_{j+1}^{n+1}+u_{j+1}^{n-1}\right)-\left(u_{j-1}^{n}\right)^{p}\left(u_{j-1}^{n+1}+u_{j-1}^{n-1}\right)\right]\left(u_{j}^{n+1}+u_{j}^{n-1}\right) \\
= & \frac{1}{8(p+2)} \sum_{j}\left[\left(u_{j}^{n}\right)^{p}\left(u_{j+1}^{n+1}+u_{j+1}^{n-1}\right)+\left(u_{j+1}^{n}\right)^{p}\left(u_{j+1}^{n+1}+u_{j+1}^{n-1}\right)\right]\left(u_{j}^{n+1}+u_{j}^{n-1}\right) \\
& \quad-\frac{1}{8(p+2)} \sum_{j}\left[\left(u_{j+1}^{n}\right)^{p}\left(u_{j}^{n+1}+u_{j}^{n-1}\right)+\left(u_{j}^{n}\right)^{p}\left(u_{j}^{n+1}+u_{j}^{n-1}\right)\right]\left(u_{j+1}^{n+1}+u_{j+1}^{n-1}\right) \\
= & 0 .
\end{aligned}
$$

Lemma 2.3 (Discrete Sobolev Inequality [16]). For any discrete function $u_{h}$ and for any given $\varepsilon>0$, there exists a constant $K(\varepsilon, n)$, depending only $\varepsilon$ and $n$, such that

$$
\left\|u^{n}\right\|_{\infty} \leq \varepsilon\left\|u_{x}^{n}\right\|+K(\varepsilon, n)\left\|u^{n}\right\|
$$

Theorem 2.4. Assume $u_{0} \in H_{0}^{1}$, then there is the estimation for the solution of difference scheme (2.3)-(2.6),

$$
\left\|u^{n}\right\| \leq C, \quad\left\|u_{x}^{n}\right\| \leq C, \quad\left\|u^{n}\right\|_{\infty} \leq C
$$

Proof. Computing the inner product of (2.3) with $2 \bar{u}^{n}$ (i.e., $u^{n+1}+u^{n-1}$ ), we obtain

$$
\begin{aligned}
& \frac{1}{2 \tau}\left(\left\|u^{n+1}\right\|^{2}-\left\|u^{n-1}\right\|^{2}\right)+\frac{1}{2 \tau}\left(\left\|u_{x}^{n+1}\right\|^{2}-\left\|u_{x}^{n-1}\right\|^{2}\right)-\left(\alpha\left(\bar{u}^{n}\right)_{x \bar{x}^{\prime}} 2 \bar{u}^{n}\right) \\
& +\beta h \sum_{j}\left(u_{j}^{n}\right)_{\widehat{x}}\left(u_{j}^{n+1}+u_{j}^{n-1}\right)+\left(\psi\left(u^{n}, \bar{u}^{n}\right), 2 \bar{u}^{n}\right)=0 .
\end{aligned}
$$

Now, computing the fourth term of the left-hand side in (2.13), we have

$$
h \sum_{j}\left(u_{j}^{n}\right)_{\hat{x}}\left(u_{j}^{n+1}+u_{j}^{n-1}\right)=h\left[\sum_{j}\left(u_{j}^{n}\right)_{\hat{x}} u_{j}^{n+1}-\sum_{j}\left(u_{j}^{n-1}\right)_{\hat{x}} u_{j}^{n}\right] .
$$


According to Lemmas 2.1 and 2.2, and using (2.14), we get

$$
\begin{gathered}
\frac{1}{2 \tau}\left(\left\|u^{n+1}\right\|^{2}-\left\|u^{n-1}\right\|^{2}\right)+\frac{1}{2 \tau}\left(\left\|u_{x}^{n+1}\right\|^{2}-\left\|u_{x}^{n-1}\right\|^{2}\right) \\
+\beta h\left[\sum_{j}\left(u_{j}^{n}\right)_{\hat{x}} u_{j}^{n+1}-\sum_{j}\left(u_{j}^{n-1}\right)_{\hat{x}} u_{j}^{n}\right] \\
=-2 \alpha\left\|\bar{u}_{x}^{n}\right\|^{2} \leq 0 .
\end{gathered}
$$

We let

$$
E^{n}=\frac{1}{2}\left(\left\|u^{n+1}\right\|^{2}+\left\|u^{n}\right\|^{2}\right)+\frac{1}{2}\left(\left\|u_{x}^{n+1}\right\|^{2}+\left\|u_{x}^{n}\right\|^{2}\right)+\beta h \tau \sum_{j}\left(u_{j}^{n}\right)_{\hat{x}} u_{j}^{n+1}
$$

It follows from (2.15) that

$$
\begin{aligned}
E^{n} & =\frac{1}{2}\left(\left\|u^{n+1}\right\|^{2}+\left\|u^{n}\right\|^{2}\right)+\frac{1}{2}\left(\left\|u_{x}^{n+1}\right\|^{2}+\left\|u_{x}^{n}\right\|^{2}\right)+\beta h \tau \sum_{j}\left(u_{j}^{n}\right)_{\widehat{x}} u_{j}^{n+1} \\
& \leq E^{n-1} \leq \cdots \leq E^{0} .
\end{aligned}
$$

Then we have

$$
\frac{1}{2}\left(\left\|u^{n+1}\right\|^{2}+\left\|u^{n}\right\|^{2}\right)+\frac{1}{2}\left(\left\|u_{x}^{n+1}\right\|^{2}+\left\|u_{x}^{n}\right\|^{2}\right) \leq C+\frac{1}{2} \beta \tau\left(\left\|u_{x}^{n}\right\|^{2}+\left\|u^{n+1}\right\|^{2}\right) .
$$

Using (2.18), we obtain

$$
\frac{1}{2}\left[(1-\beta \tau)\left\|u^{n+1}\right\|^{2}+\left\|u^{n}\right\|^{2}\right]+\frac{1}{2}\left[\left\|u_{x}^{n+1}\right\|^{2}+(1-\beta \tau)\left\|u_{x}^{n}\right\|^{2}\right] \leq C .
$$

Equation (2.19) yields

$$
\left\|u^{n}\right\| \leq C, \quad\left\|u_{x}^{n}\right\| \leq C .
$$

Using Lemma 2.3, the proof of Theorem 2.4 is completed.

Remark 2.5. Theorem 2.4 implies that scheme (2.3)-(2.6) is unconditionally stable.

\section{Solvability}

Next, we will discuss the solvability of the scheme (2.3) based on the technique of Omrani et al. [17]. 
Theorem 3.1. The finite difference scheme (2.3) is uniquely solvable.

Proof. It is obvious that $u^{0}$ and $u^{1}$ are uniquely determined by (2.4)-(2.5). Now suppose $u^{0}, u^{1}, \ldots, u^{n}(1 \leq n \leq N-1)$ be solved uniquely. Considering the equation of (2.3) for $u^{n+1}$, we have

$$
\frac{1}{2 \tau} u_{j}^{n+1}-\frac{1}{2 \tau}\left(u_{j}^{n+1}\right)_{x \bar{x}}-\frac{\alpha}{2}\left(u_{j}^{n+1}\right)_{x \bar{x}}+\frac{1}{2(p+2)}\left[\left(u_{j}^{n}\right)^{p}\left(u_{j}^{n+1}\right)_{\widehat{x}}+\left(\left(u_{j}^{n}\right)^{p} u_{j}^{n+1}\right)_{\widehat{x}}\right]=0 .
$$

Computing the inner product of (3.1) with $u^{n+1}$, we have

$$
\frac{1}{2 \tau}\left\|u^{n+1}\right\|^{2}+\frac{1}{2 \tau}\left\|u_{x}^{n+1}\right\|^{2}+\frac{\alpha}{2}\left\|u_{x}^{n+1}\right\|^{2}+\left(\phi\left(u^{n}, u^{n+1}\right), u^{n+1}\right)=0
$$

where $\phi\left(u^{n}, u^{n+1}\right)=(1 / 2(p+2))\left[\left(u_{j}^{n}\right)^{p}\left(u_{j}^{n+1}\right)_{\widehat{x}}+\left(\left(u_{j}^{n}\right)^{p} u_{j}^{n+1}\right)_{\widehat{x}}\right]$.

In view of difference properties and the boundary conditions (2.6), we obtain

$$
\begin{aligned}
\left(\phi\left(u^{n}, u^{n+1}\right), u^{n+1}\right)= & \frac{1}{2(p+2)} h \sum_{j=1}^{J-1}\left[\left(u_{j}^{n}\right)^{p}\left(u_{j}^{n+1}\right)_{\widehat{x}}+\left(\left(u_{j}^{n}\right)^{p} u_{j}^{n+1}\right)_{\widehat{x}}\right] u_{j}^{n+1} \\
= & \frac{1}{4(p+2)} h \sum_{j=1}^{J-1}\left[\left(u_{j}^{n}\right)^{p} u_{j+1}^{n+1} u_{j}^{n+1}+\left(u_{j+1}^{n}\right)^{p} u_{j+1}^{n+1} u_{j}^{n+1}\right] \\
& -\frac{1}{4(p+2)} h \sum_{j=1}^{J-1}\left[\left(u_{j}^{n}\right)^{p} u_{j-1}^{n+1} u_{j}^{n+1}+\left(u_{j-1}^{n}\right)^{p} u_{j-1}^{n+1} u_{j}^{n+1}\right] \\
= & 0 .
\end{aligned}
$$

It follows from (3.2) and (3.3) that

$$
\left\|u^{n+1}\right\|^{2}+\left\|u_{x}^{n+1}\right\|^{2}+\alpha \tau\left\|u_{x}^{n+1}\right\|^{2}=0 .
$$

Noting that $\alpha>0$ and following from (3.4), we have

$$
\left\|u^{n+1}\right\|^{2}+\left\|u_{x}^{n+1}\right\|^{2}=0
$$

That is (3.1) has only a trivial solution. Therefore, the scheme (2.3) determines $u_{j}^{n+1}$ uniquely. This completes the proof.

Remark 3.2. All results above in this paper are correct for IBV problem of the BBM-Burgers equation with finite or infinite boundary. 


\section{Convergence and Stability of the Difference Scheme}

First, we consider the truncation error of the difference scheme (2.3)-(2.6).

Suppose $v_{j}^{n}=u\left(x_{j}, t_{n}\right)$. Making use of Taylor expansion, we find

$$
\begin{gathered}
E r_{j}^{n}=\left(v_{j}^{n}\right)_{\hat{t}}-\left(v_{j}^{n}\right)_{x \bar{x} \hat{t}}-\alpha\left(\bar{v}_{j}^{n}\right)_{x \bar{x}}+\beta\left(v_{j}^{n}\right)_{\widehat{x}}+\frac{1}{p+2}\left[\left(v_{j}^{n}\right)^{p}\left(\bar{v}_{j}^{n}\right)_{\widehat{x}}+\left(\left(v_{j}^{n}\right)^{p} \bar{v}_{j}^{n}\right)_{\widehat{x}},\right. \\
u_{j}^{0}=u_{0}\left(x_{j}\right), \\
u_{j}^{1}-\left(u_{j}^{1}\right)_{x \bar{x}}=u_{0}\left(x_{j}\right)+\frac{d^{2} u_{0}}{d x^{2}}\left(x_{j}\right)-\tau\left[\beta \frac{d u_{0}}{d x}\left(x_{j}\right)-\alpha \frac{d^{2} u_{0}}{d x^{2}}\left(x_{j}\right)+u_{0}^{p}\left(x_{j}\right) \frac{d u_{0}}{d x}\left(x_{j}\right)\right]+r_{i},
\end{gathered}
$$

where $E r_{j}^{n}$ and $r_{i}$ are the truncation errors of the difference scheme (2.3)-(2.6). It can be easily obtained that (see $[18,19])$

$$
\begin{gathered}
\left|E r_{j}^{n}\right|=O\left(h^{2}+\tau^{2}\right), \\
\left|r_{j}^{n}\right|=O\left(h^{2}+\tau^{2}\right) .
\end{gathered}
$$

Lemma 4.1. Assume $u(x, t)$ is smooth enough, then the local truncation error of the finite difference scheme (2.3)-(2.6) is

$$
\left|E r_{j}^{n}\right|=O\left(h^{2}+\tau^{2}\right)
$$

Lemma 4.2 (see [16]). Suppose that the discrete function $w_{h}$ satisfies recurrence formula

$$
w_{n}-w_{n-1} \leq A \tau w_{n}+B \tau w_{n-1}+C_{n} \tau
$$

where $A, B, C_{n}(n=1, \cdots N)$ are nonnegative constants. Then

$$
\left\|w_{n}\right\|_{\infty} \leq\left(w_{0}+\tau \sum_{k=1}^{N} C_{k}\right) e^{2(A+B) \tau}
$$

where $\tau$ is small, such that $(A+B) \tau \leq((N-1) / 2 N)(N>1)$.

Theorem 4.3. Assume $u_{0} \in H_{0}^{1}\left[x_{L}, x_{R}\right]$ and $u \in C^{(4,3)}$, then the solution of the difference scheme (2.3)-(2.6) converges to the solution of the problem (1.3) with order $O\left(h^{2}+\tau^{2}\right)$ by the $\|\cdot\|_{\infty}$ norm. 
Proof. Let $e_{j}^{n}=v_{j}^{n}-u_{j}^{n}$. Subtracting (2.3)-(2.5) from (4.1)-(4.3), respectively, we have

$$
\begin{aligned}
\operatorname{Er}_{j}^{n}= & \left(e_{j}^{n}\right)_{\hat{t}}-\left(e_{j}^{n}\right)_{x \bar{x} \hat{t}}-\alpha\left(\bar{e}_{j}^{n}\right)_{x \bar{x}} \\
& +\beta\left(e_{j}^{n}\right)_{\widehat{x}}+\frac{1}{p+2}\left[\left(v_{j}^{n}\right)^{p}\left(\bar{v}_{j}^{n}\right)_{\widehat{x}}+\left(\left(v_{j}^{n}\right)^{p} \bar{v}_{j}^{n}\right)_{\widehat{x}}\right] \\
& -\frac{1}{p+2}\left[\left(u_{j}^{n}\right)^{p}\left(\bar{u}_{j}^{n}\right)_{\widehat{x}}+\left(\left(u_{j}^{n}\right)^{p} \bar{u}_{j}^{n}\right)_{\widehat{x}}\right], \\
e_{j}^{0}= & 0, \\
e_{j}^{1}= & r_{j} .
\end{aligned}
$$

For a simple notation, the last two terms of (4.7) are defined by

$$
\begin{aligned}
& I=\frac{1}{p+2}\left(v_{j}^{n}\right)^{p}\left(\bar{v}_{j}^{n}\right)_{\widehat{x}}-\frac{1}{p+2}\left(u_{j}^{n}\right)^{p}\left(\bar{u}_{j}^{n}\right)_{\widehat{x}} \\
& I I=\frac{1}{p+2}\left(\left(v_{j}^{n}\right)^{p} \bar{v}_{j}^{n}\right)_{\widehat{x}}-\frac{1}{p+2}\left(\left(u_{j}^{n}\right)^{p} \bar{u}_{j}^{n}\right)_{\widehat{x}} .
\end{aligned}
$$

Computing the inner product of (4.7) with $e^{n+1}+e^{n-1}$ (i.e., $\left.2 \bar{e}^{n}\right)$, we get

$$
\begin{aligned}
\left(E r_{j}^{n}, 2 \bar{e}^{n}\right)= & \frac{1}{2 \tau}\left(\left\|e^{n+1}\right\|^{2}-\left\|e^{n-1}\right\|^{2}\right)+\frac{1}{2 \tau}\left(\left\|e_{x}^{n+1}\right\|^{2}-\left\|e_{x}^{n-1}\right\|^{2}\right)-\left(\alpha\left(\bar{e}^{n}\right)_{x \bar{x}^{\prime}} 2 \bar{e}^{n}\right) \\
& +\beta h \sum_{j}\left(e_{j}^{n}\right)_{\widehat{x}}\left(e_{j}^{n+1}+e_{j}^{n-1}\right)+\left(I+I I, 2 \bar{e}^{n}\right) .
\end{aligned}
$$

Similarly to the proof of Theorem 2.4 , we obtain

$$
\begin{gathered}
\left(\alpha\left(\bar{e}^{n}\right)_{x \bar{x}}, 2 \bar{e}^{n}\right)=-2 \alpha\left\|\bar{e}_{x}^{n}\right\|^{2}, \\
\beta h \sum_{j}\left(e_{j}^{n}\right)_{\hat{x}}\left(e_{j}^{n+1}+e_{j}^{n-1}\right)=\beta\left[h \sum_{j}\left(e_{j}^{n}\right)_{\hat{x}} e_{j}^{n+1}-h \sum_{j}\left(e_{j-1}^{n}\right)_{\hat{x}} e_{j}^{n}\right] .
\end{gathered}
$$

According to Theorem 2.4, we obtain

$$
\begin{aligned}
\left(I, 2 \bar{e}^{n}\right) & =\frac{1}{p+2} h \sum_{j}\left[\left(v_{j}^{n}\right)^{p}\left(e_{j}^{n+1}+e_{j}^{n-1}\right)_{\hat{x}}+\left(\left(v_{j}^{n}\right)^{p}-\left(u_{j}^{n}\right)^{p}\right)\left(u_{j}^{n+1}+u_{j}^{n-1}\right)_{\hat{x}}\right]\left(e_{j}^{n+1}+e_{j}^{n-1}\right) \\
& \leq C h \sum_{j}\left[\left|\left(e_{j}^{n+1}+e_{j}^{n-1}\right)_{\hat{x}}\right|+\left|\left(u_{j}^{n+1}+u_{j}^{n-1}\right)_{\widehat{x}}\right|\right]\left(e_{j}^{n+1}+e_{j}^{n-1}\right) \\
& \leq C\left(\left\|e_{x}^{n+1}\right\|^{2}+\left\|e_{x}^{n-1}\right\|^{2}+\left\|e^{n+1}\right\|^{2}+\left\|e^{n-1}\right\|^{2}\right),
\end{aligned}
$$


Journal of Applied Mathematics

$$
\begin{aligned}
\left(I I, 2 \bar{e}^{n}\right) & =\frac{1}{p+2} \sum_{j}\left\{\left[\left(v_{j}^{n}\right)^{p}\left(e_{j}^{n+1}+e_{j}^{n-1}\right)\right]_{\widehat{x}}+\left[\left(\left(v_{j}^{n}\right)^{p}-\left(u_{j}^{n}\right)^{p}\right)\left(u_{j}^{n+1}+u_{j}^{n-1}\right)\right]_{\hat{x}}\right\}\left(e_{j}^{n+1}+e_{j}^{n-1}\right) \\
& =-\frac{1}{3} h \sum_{j}\left[\left(v_{j}^{n}\right)^{p}\left(e_{j}^{n+1}+e_{j}^{n-1}\right)+\left(\left(v_{j}^{n}\right)^{p}-\left(u_{j}^{n}\right)^{p}\right)\left(u_{j}^{n+1}+u_{j}^{n-1}\right)\right]\left(e_{j}^{n+1}+e_{j}^{n-1}\right)_{\hat{x}} \\
& \leq C h \sum_{j}\left[\left|\left(e_{j}^{n+1}+e_{j}^{n-1}\right)\right|+\left|e_{j}^{n}\right|\right]\left(e_{j}^{n+1}+e_{j}^{n-1}\right)_{\widehat{x}} \\
& \leq C\left(\left\|e_{x}^{n+1}\right\|^{2}+\left\|e_{x}^{n-1}\right\|^{2}+\left\|e^{n+1}\right\|^{2}+\left\|e^{n}\right\|^{2}+\left\|e^{n-1}\right\|^{2}\right) .
\end{aligned}
$$

In addition, there exists obviously that

$$
\left|\left(E r_{j}^{n}, e^{n+1}+e^{n-1}\right)\right| \leq\left\|E r^{n}\right\|^{2}+\frac{1}{2}\left(\left\|e^{n+1}\right\|^{2}+\left\|e^{n-1}\right\|^{2}\right) .
$$

Substituting (4.10)-(4.12) into (4.9), we have

$$
\begin{aligned}
\frac{1}{2 \tau}\left(\left\|e^{n+1}\right\|^{2}-\left\|e^{n-1}\right\|^{2}\right)+\frac{1}{2 \tau}\left(\left\|e_{x}^{n+1}\right\|^{2}-\left\|e_{x}^{n-1}\right\|^{2}\right) \\
\leq\left\|E r^{n}\right\|^{2}+\frac{1}{2}\left(\left\|e^{n+1}\right\|^{2}+\left\|e^{n-1}\right\|^{2}\right)+\beta\left\|e_{x}^{n}\right\|^{2}+\frac{1}{2} \beta\left(\left\|e^{n+1}\right\|^{2}+\left\|e^{n}\right\|^{2}\right) \\
+C\left(\left\|e_{x}^{n+1}\right\|^{2}+\left\|e_{x}^{n}\right\|^{2}+\left\|e_{x}^{n-1}\right\|^{2}+\left\|e^{n+1}\right\|^{2}+\left\|e^{n}\right\|^{2}+\left\|e^{n-1}\right\|^{2}\right) .
\end{aligned}
$$

Let

$$
B^{n}=\frac{1}{2}\left(\left\|e^{n+1}\right\|^{2}+\left\|e^{n}\right\|^{2}\right)+\frac{1}{2}\left(\left\|e_{x}^{n+1}\right\|^{2}+\left\|e_{x}^{n}\right\|^{2}\right) .
$$

Then (4.13) can be rewritten as

$$
B^{n}-B^{n-1} \leq \tau\left\|E r^{n}\right\|^{2}+C \tau\left(B^{n}+B^{n-1}\right) .
$$

By Lemma 4.2, it can immediately be obtained that

$$
B^{N} \leq\left(B^{0}+T \sup _{1 \leq n \leq N}\left\|E r^{n}\right\|^{2}\right) e^{C T} .
$$

To complete the proof, it is enough to find $B^{0}$ estimate. From (4.7), we obtain

$$
\left\|e^{0}\right\|=0
$$


Using (4.3) and (4.8), we get

$$
\left\|e^{1}\right\| \leq O\left(h^{2}+\tau^{2}\right)
$$

It follows from (4.17) and (4.18) that

$$
B^{0} \leq\left[O\left(\tau^{2}+h^{2}\right)\right]^{2}
$$

Thus

$$
\left\|e^{n}\right\| \leq O\left(\tau^{2}+h^{2}\right), \quad\left\|e_{x}^{n}\right\| \leq O\left(\tau^{2}+h^{2}\right) .
$$

According to Lemma 2.3, there exists that

$$
\left\|e^{n}\right\|_{\infty} \leq O\left(\tau^{2}+h^{2}\right) .
$$

Similarly, the following theorem can be proved.

Theorem 4.4. Under the conditions of Theorem 4.3, the solution of finite difference scheme (2.3)(2.6) is stable by the $\|\cdot\|_{\infty}$ norm.

\section{Numerical Experiments}

In this section, we will compute several numerical experiments to verify the correction of our theoretical analysis in the above sections.

Example 5.1 (see [20]). Consider the following initial-boundary problem of BBM-Burgers equation:

$$
\begin{gathered}
u_{t}-u_{x x t}-\alpha u_{x x}+u_{x}+u u_{x}=0, \quad x \in[0,1], t \in[0,10], \\
u(x, 0)=u_{0}(x), \quad x \in[0,1] \\
u(0, t)=u(1, t)=0, \quad t \in[0,10] .
\end{gathered}
$$

We denote the scheme proposed in [20] as Scheme I and the scheme (2.3) in present paper as Scheme II. In computations, we choose the initial condition $u_{0}(x)=\exp \left(-x^{2}\right)$ [20]. The maximal errors of both schemes are listed in Table 1 . We get that a second-order linear scheme is as accurate as Scheme I which is a nonlinear one.

Example 5.2 (see [13]). Consider the GBBM-Burgers equation

$$
u_{t}-u_{x x t}-\alpha u_{x x}+\beta u_{x}+u^{p} u_{x}=0, \quad x \in[0,1], t \in[0, T],
$$


Table 1: The maximal errors of numerical solutions at $t=10$ with $\tau=0.1$ for $\alpha=0.5$ when $p=1$.

\begin{tabular}{lcccc}
\hline & $h=1 / 4$ & $h=1 / 8$ & $h=1 / 16$ & $h=1 / 32$ \\
\hline Scheme I & $2.486233 e-4$ & $6.519728 e-5$ & $1.618990 e-5$ & $4.929413 e-6$ \\
Scheme II & $2.438693 e-4$ & $6.418263 e-5$ & $1.594145 e-5$ & $3.867502 e-6$ \\
\hline
\end{tabular}

Table 2: The maximal errors of numerical solutions at $t=10$ with $\tau=0.1$ for $\alpha=0.5$ when $p=4$.

\begin{tabular}{lcccc}
\hline & $h=1 / 4$ & $h=1 / 8$ & $h=1 / 16$ & $h=1 / 32$ \\
\hline Scheme II & $5.293584 e-4$ & $1.416254 e-4$ & $3.480022 e-5$ & $8.423768 e-6$ \\
Scheme III & $5.069513 e-3$ & $3.444478 e-3$ & $1.916013 e-3$ & $9.262223 e-4$ \\
\hline
\end{tabular}

Table 3: The errors of numerical solutions at $t=10$ with $\tau=0.1$ when $p=2$.

\begin{tabular}{lcccc}
\hline$h$ & $\left\|v^{n}-u^{n}\right\|$ & $\left\|v^{n}-u^{n}\right\|_{\infty}$ & $\left\|v^{n / 4}-u^{n / 4}\right\| /\left\|v^{n}-u^{n}\right\|$ & $\left\|v^{n / 4}-u^{n / 4}\right\|_{\infty} /\left\|v^{n}-u^{n}\right\|_{\infty}$ \\
\hline 0.25 & $6.377969 e-4$ & $9.352639 e-4$ & - & - \\
0.125 & $1.582597 e-4$ & $2.314686 e-4$ & 4.030065 & 4.040566 \\
0.0625 & $3.920742 e-5$ & $5.893641 e-5$ & 4.036473 & 3.927429 \\
0.03125 & $9.501117 e-6$ & $1.428261 e-5$ & 4.126612 & 4.126445 \\
\hline
\end{tabular}

Table 4: The errors of numerical solutions at $t=10$ with $\tau=0.1$ when $p=4$.

\begin{tabular}{lcccc}
\hline$h$ & $\left\|v^{n}-u^{n}\right\|$ & $\left\|v^{n}-u^{n}\right\|_{\infty}$ & $\left\|v^{n / 4}-u^{n / 4}\right\| /\left\|v^{n}-u^{n}\right\|$ & $\left\|v^{n / 4}-u^{n / 4}\right\|_{\infty} /\left\|v^{n}-u^{n}\right\|_{\infty}$ \\
\hline 0.25 & $6.316492 e-4$ & $9.262624 e-4$ & - & - \\
0.125 & $1.568213 e-4$ & $2.294480 e-4$ & 4.027828 & 4.036916 \\
0.0625 & $3.885715 e-5$ & $5.828155 e-5$ & 4.035841 & 3.936889 \\
0.03125 & $9.416614 e-6$ & $1.412454 e-5$ & 4.126446 & 4.126262 \\
\hline
\end{tabular}

with an initial condition

$$
u(x, 0)=u_{0}(x), \quad x \in[0,1]
$$

and boundary conditions

$$
u(0, t)=u(1, t)=0, \quad t \in[0, T]
$$

In computations, we choose the initial condition $u_{0}(x)=1 /\left(1+x^{4}\right)$ [13]. Without loss of generality, We take $p=2,4,8$ and $\alpha=0.5, \beta=1$. Since we do not know the exact solution of (5.4)-(5.6), an error estimate method in [21] is used. A comparison between the numerical solutions on a coarse mesh and those on a refine mesh is made. In order to obtain the error estimates, we consider the solution on mesh $h=1 / 160$ as reference solution and obtain error estimates on mesh $h=1 / 4,1 / 8,1 / 16$, and 1/32, respectively. We denote the scheme proposed in [13] as Scheme III and make a comparison with the scheme (2.3) in present paper as Scheme II when $p=4$ in Table 2. The corresponding errors in the sense of $L_{\infty}$-norm and $L_{2}$-norm are listed in Tables 3, 4, and 5, respectively. These three tables verify the second-order convergence and good stability of the numerical solutions. 
Table 5: The errors of numerical solutions at $t=10$ with $\tau=0.1$ when $p=8$.

\begin{tabular}{lcccc}
\hline$h$ & $\left\|v^{n}-u^{n}\right\|$ & $\left\|v^{n}-u^{n}\right\|_{\infty}$ & $\left\|v^{n / 4}-u^{n / 4}\right\| /\left\|v^{n}-u^{n}\right\|$ & $\left\|v^{n / 4}-u^{n / 4}\right\|_{\infty} /\left\|v^{n}-u^{n}\right\|_{\infty}$ \\
\hline 0.25 & $1.150448 e-4$ & $1.822979 e-4$ & - & - \\
0.125 & $2.981547 e-5$ & $4.674950 e-5$ & 3.858561 & 3.899462 \\
0.0625 & $7.426232 e-6$ & $1.167644 e-5$ & 4.014885 & 4.003745 \\
0.03125 & $1.801424 e-6$ & $2.879611 e-6$ & 4.122423 & 4.054867 \\
\hline
\end{tabular}

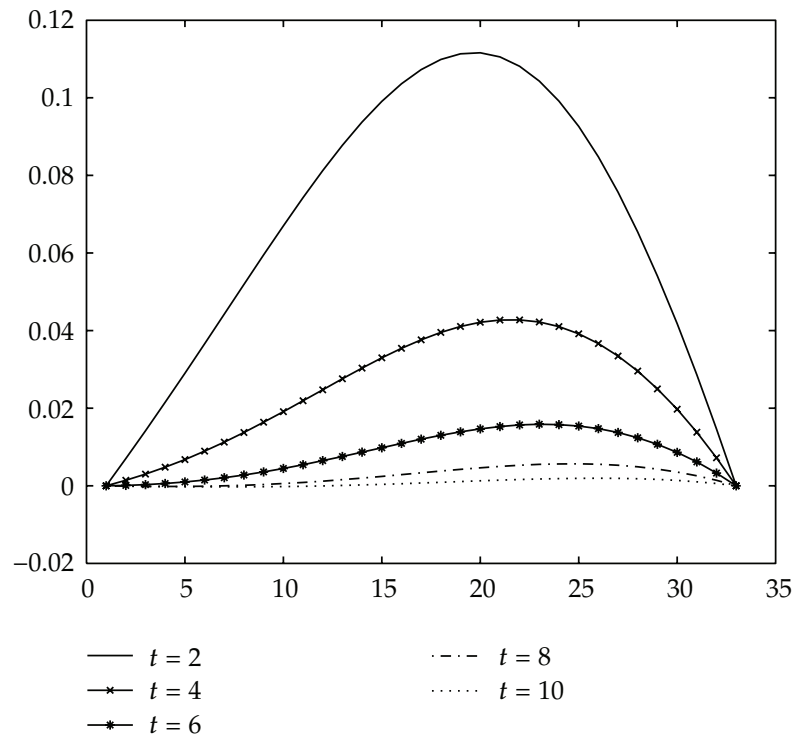

Figure 1: Numerical solution of $u(x, t)$ with $h=0.03125, \tau=0.1$ when $p=2$.

Figures 1 and 2 plot the numerical solutions computed by the linearly implicit scheme (2.3) with $\tau=0.1, h=0.03125$, and $\alpha=0.5$ when $p=2,8$ at $t=2,4,6,8$, and 10, respectively. From Figures 1 and 2, it is easy to observe that the height of the numerical approximation to $u$ is more and more low with time elapsing due to the effect of dissipative term $\alpha u_{x x}$. Both of them simulates that the continuous energy $E(t)$ of the problem (1.3) in Theorem 2.4 decreases in time. Numerical experiments show our scheme is accurate and efficient.

\section{Conclusions}

In this paper, we have presented a three-level linear-implicit finite difference scheme for the GBBM-Burgers equation, which has a wide range of applications in physics. The convergence and stability as well as second-order error estimate of the finite difference approximate solutions were discussed in detail. Numerical experiments show our scheme is accurate and efficient. 


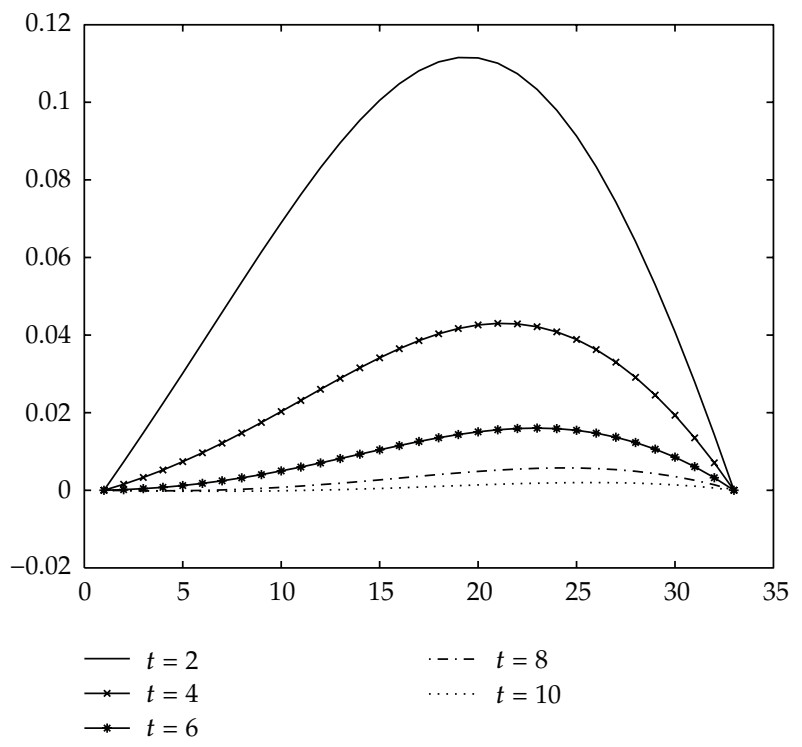

Figure 2: Numerical solution of $u(x, t)$ with $h=0.03125, \tau=0.1$ when $p=8$.

\section{Acknowledgments}

This work is supported by the fund of National Natural Science (11171193, 11171180, and 10901096) and the fund of Natural Science of Shandong Province (ZR2009AL019, ZR2011AM016), and the Youth Research Foundation of WFU (no. 2011Z17). The authors thank the referees for their valuable comments.

\section{References}

[1] K. Al-Khaled, S. Momani, and A. Alawneh, "Approximate wave solutions for generalized BenjaminBona-Mahony-Burgers equations," Applied Mathematics and Computation, vol. 171, no. 1, pp. 281-292, 2005.

[2] D. H. Peregrine, "Calculations of the development of an undular bore," The Journal of Fluid Mechanics, vol. 25, pp. 321-330, 1966.

[3] T. B. Benjamin, J. L. Bona, and J. J. Mahony, "Model equations for long waves in nonlinear dispersive systems," Philosophical Transactions of the Royal Society of London Series A, vol. 272, no. 1220, pp. 47-78, 1972.

[4] K. R. Raslan, "A computational method for the regularized long wave (RLW) equation," Applied Mathematics and Computation, vol. 167, no. 2, pp. 1101-1118, 2005.

[5] D. Bhardwaj and R. Shankar, "A computational method for regularized long wave equation," Computers \& Mathematics with Applications, vol. 40, no. 12, pp. 1397-1404, 2000.

[6] D. Kaya, "A numerical simulation of solitary-wave solutions of the generalized regularized longwave equation," Applied Mathematics and Computation, vol. 149, no. 3, pp. 833-841, 2004.

[7] S. Abbasbandy, "Homotopy analysis method for generalized Benjamin-Bona-Mahony equation," ZAMP: Zeitschrift für Angewandte Mathematik und Physik, vol. 59, no. 1, pp. 51-62, 2008.

[8] N. Hayashi, E. I. Kaikina, and P. I. Naumkin, "Large time asymptotics for the BBM-Burgers equation," Annales Henri Poincaré, vol. 8, no. 3, pp. 485-511, 2007.

[9] M.-n. Jiang and Y.-l. Xu, "Asymptotic behavior of solutions to the generalized BBM-Burgers equation," Acta Mathematicae Applicatae Sinica. English Series, vol. 21, no. 1, pp. 31-42, 2005.

[10] H. Yin, S. Chen, and J. Jin, "Convergence rate to traveling waves for generalized Benjamin-BonaMahony-Burgers equations," ZAMP: Zeitschrift für Angewandte Mathematik und Physik, vol. 59, no. 6, pp. 969-1001, 2008. 
[11] M. Mei, "Large-time behavior of solution for generalized Benjamin-Bona-Mahony-Burgers equations," Nonlinear Analysis: Theory, Methods \& Applications, vol. 33, no. 7, pp. 699-714, 1998.

[12] C. I. Kondo and C. M. Webler, "Higher-order for the multidimensional generalized BBM-Burgers equation: existence and convergence results," Acta Applicandae Mathematicae, vol. 111, no. 1, pp. 45$64,2010$.

[13] S.-I. Kinami, M. Mei, and S. Omata, "Convergence to diffusion waves of the solutions for BenjaminBona-Mahony-Burgers equations," Applicable Analysis, vol. 75, no. 3-4, pp. 317-340, 2000.

[14] L. Zhang, "A finite difference scheme for generalized regularized long-wave equation," Applied Mathematics and Computation, vol. 168, no. 2, pp. 962-972, 2005.

[15] J. Hu and K. Zheng, "Two conservative difference schemes for the generalized Rosenau equation," Boundary Value Problems, vol. 2010, Article ID 543503, 18 pages, 2010.

[16] Y. L. Zhou, Application of Discrete Functional Analysis to the Finite Difference Method, International Academic Publishers, Beijing, China, 1991.

[17] K. Omrani, F. Abidi, T. Achouri, and N. Khiari, "A new conservative finite difference scheme for the Rosenau equation," Applied Mathematics and Computation, vol. 201, no. 1-2, pp. 35-43, 2008.

[18] K. Omrani, "Numerical methods and error analysis for the nonlinear Sivashinsky equation," Applied Mathematics and Computation, vol. 189, no. 1, pp. 949-962, 2007.

[19] N. Khiari, T. Achouri, M. L. Ben Mohamed, and K. Omrani, "Finite difference approximate solutions for the Cahn-Hilliard equation," Numerical Methods for Partial Differential Equations, vol. 23, no. 2, pp. 437-455, 2007.

[20] K. Omrani and M. Ayadi, "Finite difference discretization of the Benjamin-Bona-Mahony-Burgers equation," Numerical Methods for Partial Differential Equations, vol. 24, no. 1, pp. 239-248, 2008.

[21] R. C. Mittal and G. Arora, "Quintic B-spline collocation method for numerical solution of the extended Fisher-Kolmogorov equation," International Journal of Applied Mathematics and Mechanics, vol. 6, no. 1, pp. 74-85, 2010. 


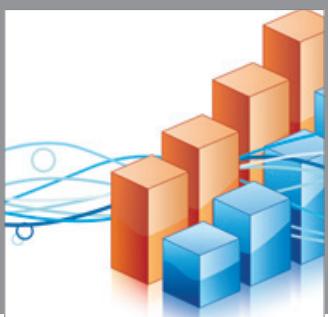

Advances in

Operations Research

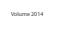

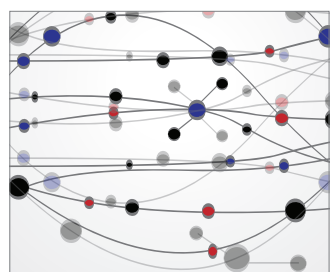

\section{The Scientific} World Journal
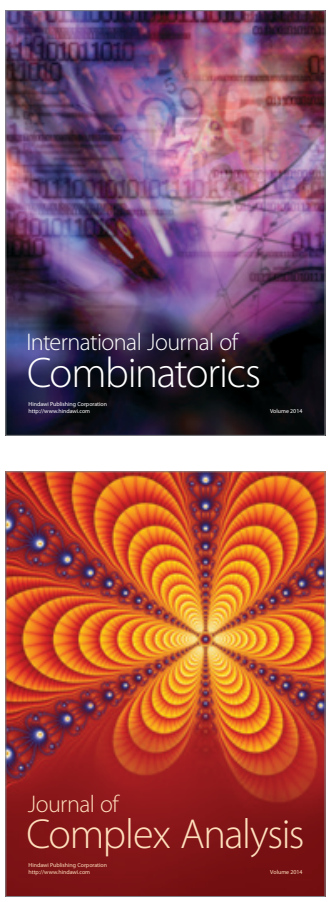

International Journal of

Mathematics and

Mathematical

Sciences
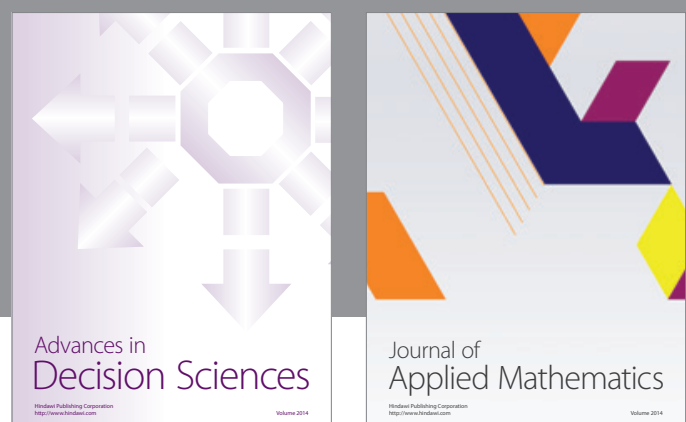

Journal of

Applied Mathematics
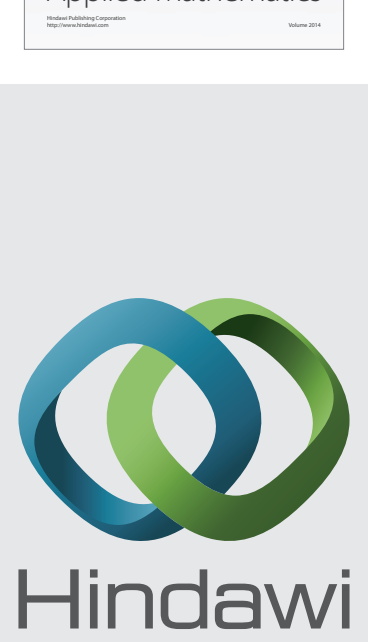

Submit your manuscripts at http://www.hindawi.com
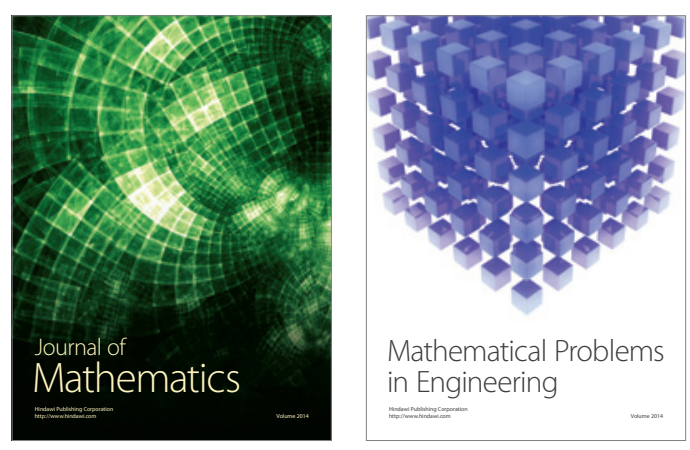

Mathematical Problems in Engineering
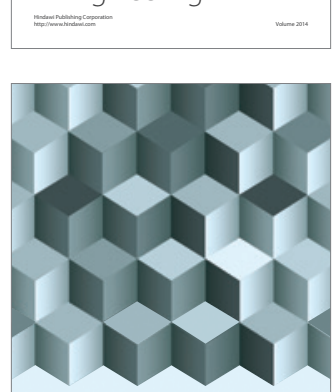

Journal of

Function Spaces
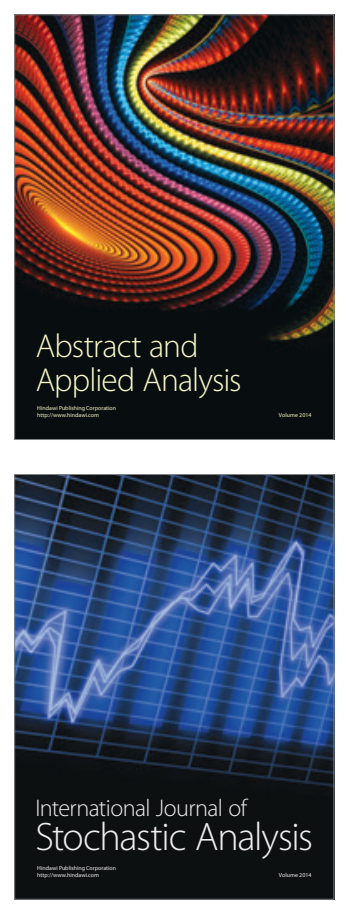

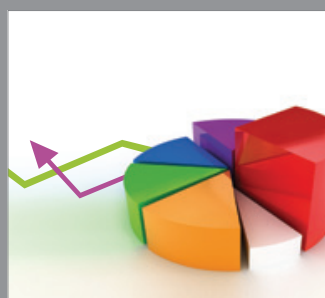

ournal of

Probability and Statistics

Promensencen
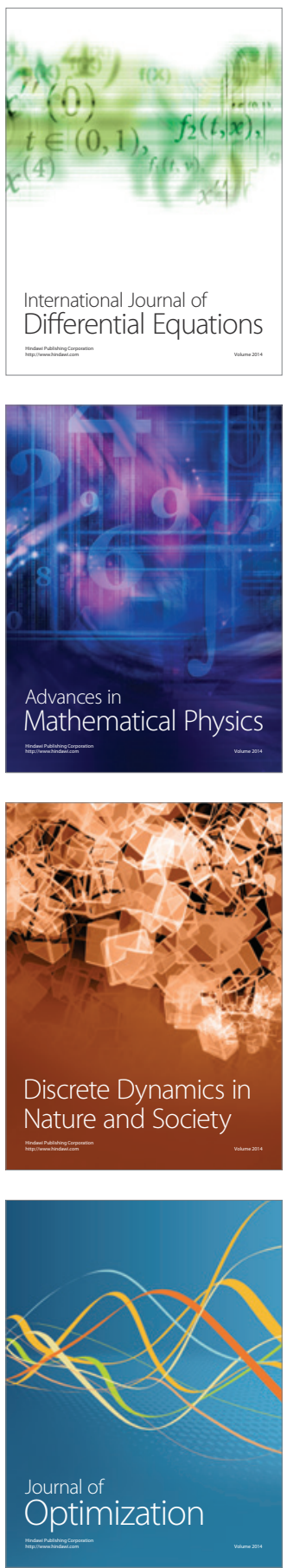